\title{
Analisando títulos desviantes do jornalismo popular à luz da teoria da relevância
}

\author{
Wagner Alexandre dos Santos Costa ${ }^{1}$ \\ Universidade Federal Rural do Rio de Janeiro
}

Resumo: Neste artigo, apresentamos um estudo sobre a relação entre as informações oferecidas ao leitor e os conhecimentos por ele mobilizados na leitura de títulos de notícias do jornal popular Meia Hora. Utilizamos a Teoria da Relevância, de Dan Sperber e Deirdre Wilson (2005), para analisar a realização de processos cognitivo-inferenciais empregados na construção de uma hipótese desviante de leitura no processamento do texto. De acordo com a teoria, são os processos não inferenciais que constituem a base para os processos inferenciais, nos quais tanto o conhecimento do leitor quanto o contexto figuram como fundamentais no processamento do texto. Certos títulos no jornalismo popular, portanto, para serem interpretados como unidades complexas desviantes, requerem o levantamento de informações variadas (verbais e não verbais) da superfície textual e mobilizam processos inferenciais contextuais complementares. De um corpus coletado entre os anos 2010 e 2013, selecionamos três ocorrências para demonstrar que os referidos títulos contêm inputs inclinados a conclusões distantes do tema global da notícia. Tais elementos, que se materializaram em imagens, cores e signos verbais, são capazes de figurar como centrais no processo cognitivo de elaboração de hipóteses de leitura na atividade inicial de processamento do texto. Produzem, na relação com o conhecimento armazenado, inferências que só poderão ser reformuladas com base no processamento de categorias textuais seguintes.

Palavras-chave: Jornalismo popular. Processamento do texto. Teoria da Relevância.

\section{Considerações iniciais}

Em relação ao texto noticioso, a tradição tem preconizado, haja vista os vários manuais de redação disponíveis, o estilo claro e conciso, prioritariamente referencial, de modo que o redator deve evitar ao máximo a linguagem opaca e ambígua.

No entanto, mesmo num discurso como o jornalístico, pretensiosamente referencial, encontram-se nas notícias, frequentemente, enunciados que se valem da linguagem figurada e estabelecem mais de um nível de significação. Um que se aproxima do fato noticiado (seja com linguagem mais referencial, seja com linguagem mais figurada); outro que constitui o

\footnotetext{
${ }^{1}$ Wagner Alexandre dos Santos Costa é doutor em Estudos da Linguagem pela Universidade Federal Fluminense (UFF) e professor do Instituto de Ciências Humanas e Sociais/ Departamento de Letras e Comunicação (ICHS/DLC) da Universidade Federal Rural do Rio de Janeiro (UFRRJ). Participa dos seguintes grupos de pesquisa: Interação, cognição e gramática (INTEGRA/UFF) e Estudos Linguísticos, Multiletramentos e Ensino de português (ELMEP/UFRRJ).
} 
desviante, a representar outra oferta de interpretação (COSTA, 2013), às vezes, por meio de recursos variados, como o da intertextualidade (COSTA; MENEZES, 2014).

O noticiário no jornalismo popular, foco de nossos estudos, insere-se neste quadro, no qual uma gama de recursos de linguagem costuma ser superposta na elaboração de sentidos que perpassam a narração do fato noticiado. Algumas notícias, então, incorporam elementos de captação (CHARAUDEAU, 2010) paralelos, próprios desse universo comunicativo proposto pelo jornal. Assim, são mobilizadas estratégias de pôr em cena certos valoresnotícia, como os do entretenimento e do drama (AMARAL, 2006, p. 63), que consistem, respectivamente, no emprego de um tom humorístico ou emocional, que podem, por exemplo, consubstanciar-se no tema ou no como o texto é construído.

Nosso objetivo, neste artigo, é evidenciar a referida estratégia de construção presente em alguns textos do jornalismo popular (AMARAL, 2006), sobretudo no que respeita ao que entendemos por títulos desviantes ${ }^{2}$ (COSTA, 2013 e 2015). Pretendemos, principalmente, explicar como ocorre o fenômeno apoiando-nos no instrumental analítico de uma teoria cognitiva que explica a atividade do processamento do texto a partir de processos cognitivos gerados entre as pistas salientes oferecidas pelo enunciado e pelo contexto e as informações disponíveis ativadas pelo leitor.

Dessa forma, utilizamos a Teoria da relevância (SPERBER; WILSON, 2005) para demonstrar que os inputs, concentrados no título e/ou nas imagens, oferecidos como elementos relevantes a serem considerados pelo leitor no processamento do texto são, no caso em tela, dados desviantes de interpretação do conteúdo. Ou seja, diferente de oferecer pistas textuais em direção ao tema global da notícia, desfocam a atividade cognitiva (KLEIMAN, 2008) de antecipação realizada pelo leitor para uma hipótese de leitura que não representa aquela a ser desenvolvida na notícia. Assim, acreditamos que uma análise de base inferencial pode nos oferecer importante contribuição aos estudos de caráter mais textual, conforme propôs Rauen (2003).

Para tanto, analisamos três ocorrências extraídas do jornal Meia Hora, a saber: $1^{\text {a }}$ ) uma capa de jornal cuja manchete foi Eliéser é bi (20/2/2010), 2 $2^{\mathrm{a}}$ ) uma notícia da editoria Plantão de polícia, cujo título foi Bope vai às compras na Mangueira (22/5/2011) e $3^{\text {a }}$ ) outra notícia, agora da editoria Deu a louca no mundo, intitulada Barbie ganha vida (1\%/9/2011).

\footnotetext{
${ }^{2} \mathrm{O}$ conceito foi estudado e desenvolvido por Costa (2013 e 2015). Trata-se da estratégia comunicativa observada no jornalismo de caráter popular de operar a construção do título de modo que não antecipe o conteúdo semântico do texto, como tradicionalmente a ele caberia.
} 
R E V I S T A Estudos Linguísticos - N. 30-2015.2 - Wagner Alexandre dos Santos Costa

Este texto está organizado da seguinte maneira: a primeira seção constitui a fundamentação teórica, na qual delineamos aspectos centrais da Teoria da Relevância. Em seguida, na segunda seção, trazemos a análise dos textos à luz dos conceitos dessa teoria. Por fim, apresentamos nossas considerações finais.

\section{O que diz a teoria da relevância?}

Propondo uma revisão do Princípio de Cooperação e da máxima da Relação de Grice (1982[1975]), Sperber e Wilson (2005, p. 221-168) ${ }^{3}$ desenvolvem um modelo de análise da comunicação a partir do pressuposto de que no ato de linguagem o enunciador oferece evidências do conteúdo a significar, inferido pelo enunciatário com base em tais pistas. Conforme essa perspectiva, o processamento e o armazenamento da informação constroem-se na convergência de vários elementos acionados, não apenas com base em enunciados literais. Assim, a ideia central da Teoria da Relevância (TR, daqui em diante) é que essas evidências geram expectativas que guiam o processo de leitura e compreensão.

Segundo os autores Sperber e Wilson (2005, p.223), o enunciado contém um input (uma visão, um som, um enunciado, uma memória) que se conecta a uma informação disponível de modo que gerem conclusões importantes para o indivíduo. Elas podem produzir efeitos cognitivos positivos, ou seja, elas podem esclarecer dúvidas, modificar conceitos, confirmar/alterar hipóteses e rever equívocos.

De acordo com a TR, os inputs não devem ser considerados de modo isolado, mas em conjunto com o contexto, só dessa forma poderão produzir implicaturas contextuais, que são conclusões dedutíveis dessa associação. Esses inputs podem ser diversos (elementos visuais e/ou verbais, no caso do texto jornalístico impresso) e ocorrer simultaneamente. No entanto, será mais relevante aquele que produzir maior quantidade de efeitos cognitivos.

Pensamos, então, por um lado, que se um input oferecido no título de uma notícia gerar expectativas que não contribuam para a compreensão do seu tema, aquele será pouco relevante em relação ao objetivo de se apurar o conteúdo semântico do texto. Por outro lado, adquirirá relevância nesse momento inicial da atividade de processamento do texto, já que o leitor ainda não completou a leitura deste, podendo apenas aventar hipóteses quanto ao seu conteúdo semântico.

\footnotetext{
${ }^{3}$ Uma versão mais detalhada foi publicada em sua primeira edição em Relevance: communication and cognition . Cambridge, MA.: Blackwell; Oxford; Harvard University Press, 1986 (2. ed. Oxford: Blackwell, 1995).
} 
Quanto à relevância do input, ela pode, em contextos idênticos, ser calculada mediante: a) os efeitos cognitivos produzidos por ele e b) o esforço de seu processamento. Quer dizer, quanto mais efeitos cognitivos positivos o input gerar, maior será sua relevância. Por outro lado, quanto maior for a dificuldade de seu processamento, menor relevância terá (SPERBER e WILSON, 2005, p. 225).

Sendo assim, seguindo a TR e adaptando seus princípios ao nosso corpus, acreditamos que o grau de relevância atribuído ao título pode ser inferido conforme: a) a quantidade de efeitos cognitivos e de implicaturas contextuais que direcione ao tema da notícia ele for capaz de gerar; e b) o esforço de seu processamento [se + metafórico, maior o esforço; se metafórico, menor o esforço].

A TR afirma que os seres humanos têm uma tendência natural à maximização da relevância. A par disso, podem-se produzir estímulos possivelmente atrativos para orientar a compreensão de um enunciado na direção pretendida, explorando a tendência cognitiva de maximizar a relevância. Faz-se isso a partir de estímulos ostensivos, aqueles estímulos que são projetados pelo enunciador para atrair a atenção da audiência, como podemos observar no noticiário do jornal popular Meia Hora.

Um estímulo ostensivo (saliente) pode ser usado para encorajar sua audiência a considerá-lo suficientemente relevante para ser processado, p. ex., a reprodução das imagens na capa do jornal; as manchetes e mesmo os títulos das notícias nas seções internas do jornal podem ser elaborados como estímulos ostensivos para os leitores. Segundo Sperber e Wilson (2005, p. 230), a audiência tem o direito à expectativa de que input seja realmente relevante e que ele comunique, de fato, a intenção do enunciador. Então, um comunicador que deseja ser compreendido necessita

[...] dentro dos limites de suas próprias capacidades e preferências, fazer com que seu estímulo ostensivo seja tão fácil quanto possível para a audiência compreendê-lo, e fornecer evidência não somente para efeitos cognitivos que ele objetiva alcançar, mas também para efeitos cognitivos posteriores que, por manter a atenção da audiência, ajudarão a alcançar sua meta.

Por decorrência, não seria lógico o falante intentar propositalmente a assimetria entre o que comunica e o que compreende o ouvinte, a não ser por um propósito de captar a atenção deste, o que se justificaria como uma estratégia. Espera-se, portanto, que o falante formule seu enunciado de modo que a primeira interpretação que satisfaça a expectativa de relevância do ouvinte seja aquela que realmente deseja comunicar. 
Conforme explicam os autores (ibidem, p. 235), o procedimento de compreensão à luz da relevância deve ser aplicado da mesma maneira para resolver indeterminações linguísticas tanto no nível explícito quanto no implícito. Dessa forma, cabe ao ouvinte tentar reconstruir a presunção de relevância transmitida pelo enunciado, o que inclui subprocedimentos como:

a- Construção de uma hipótese apropriada sobre o conteúdo explícito (EXPLICATURAS) por meio da decodificação, desambiguização, resolução de referência e outros processos de enriquecimento pragmáticos.

b- Construção de uma hipótese apropriada sobre suposições contextuais pretendidas (PREMISSAS IMPLICADAS).

c- Construção de uma hipótese apropriada sobre implicações contextuais pretendidas (CONCLUSÕES IMPLICADAS). (Idem, ibidem).

As explicaturas correspondem, então, ao conteúdo proposicional decorrente da atribuição de significado às formas linguísticas, resultam da manipulação dos elementos da superfície textual. As implicaturas, por seu turno, resultam da interação entre tais proposições e as informações cognitivamente disponíveis aos interactantes.

Enfim, segue-se, portanto, que a compreensão é um procedimento on-line, e hipóteses sobre explicaturas, premissas implicadas e conclusões implicadas são desenvolvidas simultaneamente a partir de um background de expectativas que podem ser revisadas ou elaboradas à medida que o ouvinte/leitor vai processando o enunciado. É o que veremos na seção seguinte, ao analisarmos textos do jornalismo popular.

\section{O desvio pelo viés da teoria da relevância}

\subsection{Considerações metodológicas}

No presente estudo, partimos do pressuposto de que a construção de títulos desviantes constitui uma estratégia de captação do leitorado, conforme demonstrado em Costa (2013, 2014 e 2015), que analisou notícias do jornal popular Meia Hora. Nosso objetivo é, em acréscimo, demonstrar como certas informações, inputs, são capazes de gerar conclusões vinculadas a sentidos desviantes.

Em relação ao papel da teoria que nos dá aporte, a nosso ver, enfatizamos que os estímulos ostensivos oferecidos para o leitor constituem elementos de relevância geradores de hipóteses desviantes de leitura pretendidas pelo jornal. Como tais formulações ocorrem em um estágio inicial do processo de leitura, cumpre-se o papel desses elementos: chamar a atenção do leitor para esta categoria da notícia (o título), local onde o jornal geralmente 
R E V I S T A Estudos Linguísticos - N. 30 - 2015.2 - Wagner Alexandre dos Santos Costa

desenvolve sua estratégia de captação, propondo uma leitura supostamente atraente via entretenimento ou drama.

A concepção de leitura que subjaz ao estudo, de acordo com Kleiman (2010), corresponde a um processo psicológico em que o leitor utiliza diversas estratégias baseadas no seu conhecimento linguístico, sociocultural e enciclopédico. Ela envolve a mobilização e a interação de diversos níveis de conhecimento, o que exige operações cognitivas diversas de ordem superior.

Dessa forma, as ocorrências por nós selecionadas foram as seguintes: ${ }^{4}$

\begin{tabular}{|l|l|}
\hline Eliéser é bi & $20 / 2 / 2010$ \\
\hline Bope vai às compras na Mangueira & $22 / 5 / 2011$ \\
\hline Barbie ganha vida & $1 \% / 9 / 2011$ \\
\hline
\end{tabular}

Então, após essas breves considerações de caráter metodológico, segue-se a análise qualitativa do material:

\subsection{Análise dos textos}

Texto 1: Eliéser é bi

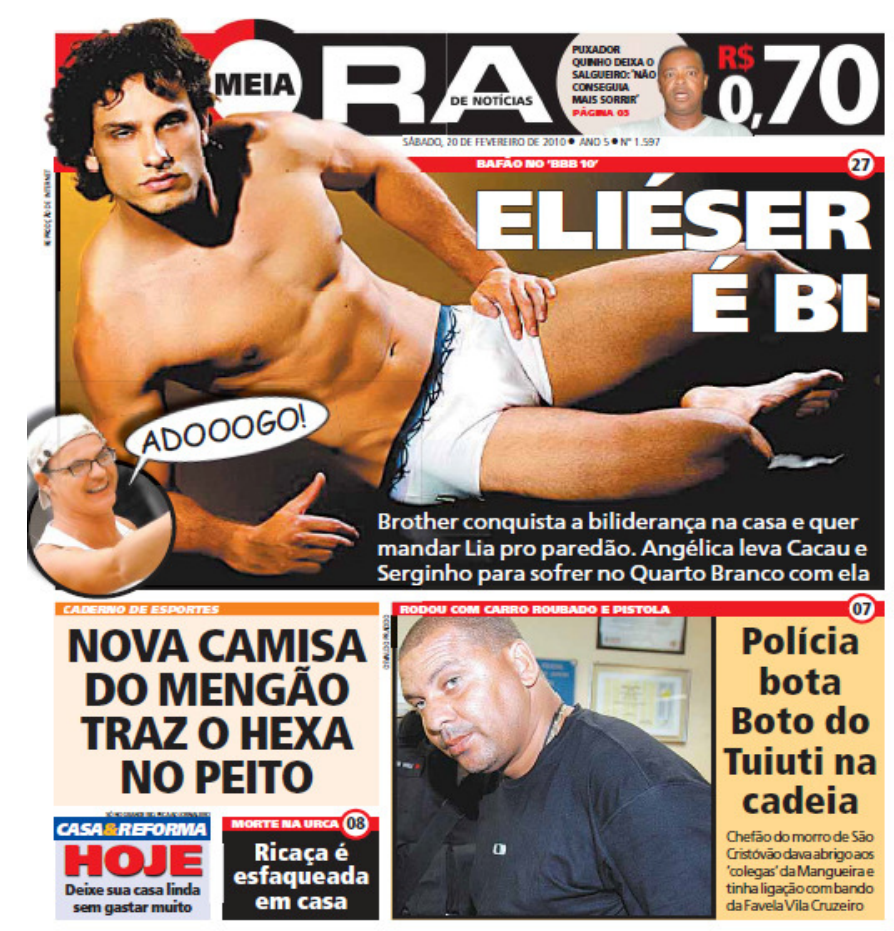

Imagem 1: Capa Meia Hora

Fonte: $<$ http://www.kibeloco.com.br/2010/02/20/quem-faz-a-fama-parte-3/>. Acesso em: 25 Ago. 2015

\footnotetext{
${ }^{4}$ Essas ocorrências foram selecionadas de um corpus de notícias reunido entre os anos de 2010 e 2013. 
Nessa manchete, destaca-se a polissemia do elemento $b i$, prefixo que na linguagem coloquial pode ocorrer como forma livre em vários contextos: Fulano é bi [bissexual]; Meu time é bi [bicampeão], significando duplo, dobro, duas vezes. É a mesma forma que, também, popularmente corresponde à redução do vocábulo bicha, pejorativo em referência a homossexual. Com base nessa forma explícita, o leitor, a seu turno, elabora provisoriamente a construção de uma hipótese, uma explicatura, segundo Sperber e Wilson (2005, p. 235).

Veja-se que as letras garrafais da manchete são um estímulo importante à relevância. Elas se opõem ao subtítulo de letras pequenas, portanto visualmente privilegiadas, sendo oferecidas para leitura antes dele e constituem, por instantes, um elemento a ser decifrado: Eliéser seria bicampeão? Eliéser seria bissexual?

Conforme se confere sequencialmente no subtítulo, ou resumo, apresentado logo após o título, orienta-se tematicamente a notícia. Assim, ela parece não se referir à orientação sexual do participante do programa, mas à sua sequência de duas vitórias na liderança no grupo.

Todavia há estímulos ostensivos notadamente enviesados que reforçam a hipótese de interpretação desviante, sobretudo os visuais. Observe-se, por exemplo, o destaque dado à estética masculina privilegiada do participante do Big Brother Brasil 10 (BBB10), supervalorizada no universo gay, e a inclusão da foto de Dicésar, participante do Big Brother Brasil 12 (BBB12), assumidamente homossexual, enunciando que adora [neste caso, inferese, em relação à hipótese de Eliéser ser bissexual], o que se encontra no balão, na forma "adooogo" (também uma alusão ao fato de Dicésar ser gago). Trata-se de suposições contextuais implicadas, que ocorrem num plano inferencial mais profundo (SPERBER e WILSON, 2005).

Além disso, se retirássemos o subtítulo, a interpretação mais provável seria a desviante, pragmaticamente motivada talvez por outra hipótese relativa à competência comunicativa do falante: a de que as ocorrências livres desse vocábulo bi (sem a presença de especificadores no contexto) em referência a pessoas signifique orientação sexual. Se, por outro lado, no caso em questão, a intenção comunicativa fosse construir sentidos de duplo, as construções mais comuns seriam do tipo $[\mathrm{bi}+x]$, como em bicampeão ou bilíder. Outra possibilidade, se se quisesse evitar a ambivalência de $b i$, seria o uso da palavra bissexual. No entanto, a opção foi por manter em aberto o sentido de bi, fato que em si já evidencia a proposta do jornal. 
R E V I S T A Estudos Linguísticos - N. 30 - 2015.2-Wagner Alexandre dos Santos Costa

Como exemplo recorrente do mesmo recurso adotado pelo jornal, veja-se adicionalmente o caso recente de Anderson Silva é bi, publicado na editoria Na marca do pênalti em 13/2/2015:

\section{ARANHA ENROLADO NA TEIA Anderson Silva é bi}

\footnotetext{
Imagem 2: Notícia

Fonte: $<$ http://www.meiahora.ig.com.br/noticias/anderson-silva-e-bi_10571.html> . Acesso em: 30 Ago. 2015.
}

Pela segunda vez, Spider é flagrado no antidoping. Novo exame foi feito depois da última luta

no qual, para além das mesmas considerações feitas sobre o material linguístico de Eliéser é bi, notam-se, ainda, inputs não-verbais que inclinam a atividade de inferenciação a conclusões implicadas (as pretendidas pelo jornal).

Assim, o fundo cor de rosa somado à mão posicionada no queixo movem o leitor em direção à construção da hipótese de que o título antecipa um tema acerca da sexualidade do lutador, o que se desfaz após a leitura do subtítulo.

Texto 2: Bope vai às compras na Mangueira 

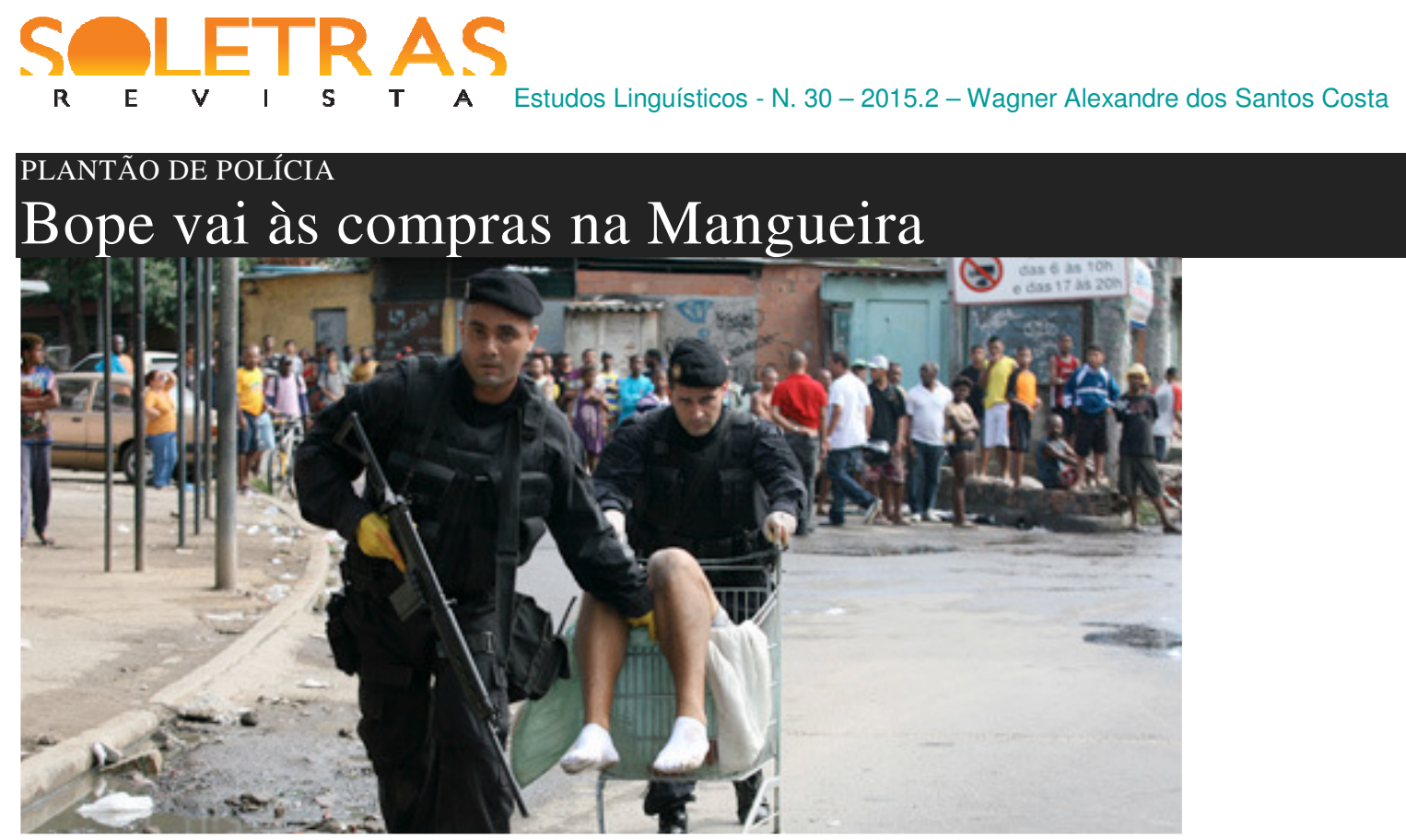

Imagem 3: Notícia

Fonte: $<$ http://www.meiahora.ig.com.br/noticias/bope-vai-as-compras-na-mangueira_3015.html> . Acesso em: 20 Ago. 2015.

Em operação, polícia mata um suspeito de tráfico. Seis pessoas foram presas

Um homem suspeito de ser traficante morreu e outro ficou ferido com tiro na perna durante operação, que começou às $8 \mathrm{~h}$ de ontem, com cerca de 70 caveiras do Batalhão de Operações Especiais (Bope) da Polícia Militar no Morro da Mangueira e na favela vizinha do Tuiuti, em São Cristóvão. Os PMs tiveram auxílio de dois blindados.

Seis pessoas foram presas. A Mangueira deve receber uma Unidade de Polícia Pacificadora (UPP) até o fim deste ano.

Um suspeito acabou preso com uma pistola 9mm. Enquanto o conduziam para a delegacia, policiais militares foram abordados por um homem e duas mulheres, que ofereceram $R \$ 10$ mil numa tentativa de suborno pela libertação do suspeito. Acabou indo todo mundo em cana. O quinto preso foi capturado após a polícia checar que ele era foragido da Justiça - ele tentou passar pelos policiais sem ser visto e chegou a mostrar o local onde trabalhava, um trailer no pé do morro, mas não adiantou.

O sexto capturado é o homem ferido com tiro na perna. Os policiais também apreenderam um fuzil, duas pistolas, munição, três celulares e dois tabletes de maconha. Na localidade do Buraco Quente, onde estava acontecendo um baile funk no momento da operação do Bope, um homem morreu em confronto com policiais. $O$ corpo foi retirado da comunidade em um carrinho de supermercado. Moradores, indignados com a ação da PM, jogaram pedras e tijolos em retaliação.

O exemplo acima, Bope vai às compras na Mangueira, mobiliza, no mínimo, duas possibilidades de leitura/interpretação, ambas assentadas no conhecimento de que o Bope (Batalhão de Operações Especiais) trabalha no combate direto ao crime, em situações consideradas de alto risco e de que isso resulta, comumente, em prisões e mortes de criminosos e/ou inocentes. A primeira (possível) interpretação refere-se à prisão de seis pessoas no local do confronto, conforme a leitura do subtítulo e do texto informam. A segunda sugere, a partir de um trecho do final da notícia, ter sido desumana a operação do Bope: “(...) um homem morreu em confronto com policiais. O corpo foi retirado da 
comunidade em um carrinho de supermercado", conforme é reforçado por elementos visuais.

Ainda que o leitor complete a leitura de todas as partes da notícia e compreenda o recorte feito no seu desenvolvimento (o fato de o carrinho apenas constituir um meio de transporte para o corpo), permanecerá a possibilidade de interpretação oferecida via ironia (a função de matar, sub-repticiamente atribuída aos policiais). Ademais, como dizem Silveira e Feltes (1999, p. 37), as pessoas atribuem importância a estímulos que, de certa forma, ajustem-se aos seus interesses.

A mensagem segunda, subliminar (mas não menos importante), foi construída e plantada com base na associação de dois estímulos: um verbal - no título, o substantivo compras - e outro visual - a imagem do corpo no carrinho de supermercado, que são explicaturas, nos termos da TR (SPERBER e WILSON, 2005), fornecidas como relevância para o leitor. Este opera a seleção de informações que envolverá no processamento do texto (o frame em que o carrinho se insere, o histórico de violência policial em localidades pobres etc.), associa-as e infere um conteúdo em conformidade ao proposto (ou não), levando-se em consideração que a interpretação selecionada pelo leitor corresponde àquela em que ele encontrou mais estímulos cognitivos.

O título, de tal forma, motiva essas operações mentais do leitor. Ainda que a hipótese de operação desumana seja destituída (o que, no contexto, faria do título elemento desviante), importa-nos ressaltar a estratégia dramática de já no título ofertar um input verbal associado a uma referência visual que, conjuntamente, conferem relevo (idem, ibidem) a tal interpretação.

No tocante a essa última consideração, Campos (2008, p. 17), ao discutir a relação entre a TR e a Cultura de massa, questiona-se sobre o sensacionalismo em alguns segmentos dessa cultura e arrisca dizer que o processamento emocional é de mais baixo custo, portanto elevaria o teor de relevância no enunciado. Isto justificaria a constante opção pelo drama na conquista pela atenção do leitor, exemplificada tanto pela ocorrência anterior, Bope vai às compras na Mangueira, como pela seguinte, Barbie ganha vida.

Texto 3: Barbie ganha vida 


\section{Mãe coloca seios falsos em filha de apenas 4 anos}

Uma americana gerou muita polêmica nos Estados Unidos, ao colocar seios e bumbum falsos em sua filhinha de apenas quatro anos, para que a criança participasse de prova num concurso de beleza infantil. A ideia da mãe, Lindsay Jackson, era fazer a pequena Maddy Jackson parecer a cantora americana Dolly Parton. Por isso, deixou a menina com aparência de mulher adulta.

No concurso, a garotinha também usou uma maquiagem pesada e peruca. Também vestiu um tipo de macacão bem justo ao corpo. As imagens foram exibidas em um reality show da TV NBC. Lá, eles mostram o dia a dia de crianças que participam de competições de beleza.

Em entrevista à apresentadora do programa, Lindsay disse que isso é normal para ela e sua filha e que não vê exagero algum.

"Para algumas pessoas, é um exagero, mas para nós isso acontece... Quando ela usa os seios e o bumbum falsos, ganha um bônus", afirmou.

Mas nem todos concordam com Lindsay Jackson. Até mesmo o estilista da menina, Michael Booth, considera os enchimentos um exagero.

"Eu não sou um grande fã do equipamento nos seios dela. Ela é muito jovem, mas espero que os juízes encarem isso como de bom gosto", disse.

Alguns grupos chegaram a lançar protestos no Facebook contra as competições, ganhando cada dia mais adeptos.

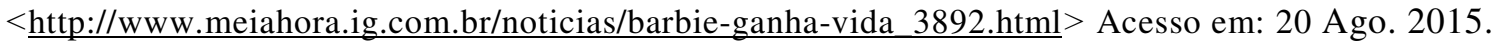

O título desta notícia informa algo possivelmente estranho, impossível para o quadro de referências sobre o mundo real, que constitui parte do conhecimento armazenado na memória do leitor: a famosa boneca Barbie viver. Então, supõe-se que o leitor, a despeito do estímulo oferecido, desconsidere esta hipótese inicial de leitura (KLEIMAN, 2008) e procure atribuir outro sentido a tal título.

Não sendo a atribuição de coerência a um enunciado algo uniforme entre as pessoas, já que isto envolve todas as experiências vivenciadas por um sujeito na atividade de formulação de explicaturas (SPERBER e WILSON, 2005), é possível o leitor não poder ativar em sua memória a informação de que Barbie é uma boneca, não possuir tal informação. Ou, por outra hipótese, ele pode supor algum tipo de experiência científica, mas dificilmente a aquisição de vida humana pela boneca.

Seja qual for a inferência realizada pelo leitor, ele teve de lidar com essa questão a resolver, uma vez que lhe foram oferecidos estímulos para colocá-lo nessa situação. Não foi possível ao leitor realizar um movimento mais rápido de passagem de leitura do título para o subtítulo e depois para o texto, então deve seguir à tarefa de checagem dessas hipóteses (KLEIMAN, 2008).

Como tradicionalmente se esperaria do título, caberá ao subtítulo o papel de redirecionar, com estímulos ótimos (SPERBER e WILSON, 2005), o leitor a inferir o conteúdo semântico do texto. 
Em outras palavras, o subtítulo Mãe coloca seios falsos em filha de apenas 4 anos é que vai cumprir, no caso dessa notícia, a função de antecipar o tema global do texto, pois comporta o cerne da notícia.

A relação metafórica entre a boneca Barbie e a menina de quatro anos consiste na composição de um figurino adulto-ousado em uma criança. Então, a imagem da menina travestida de adulta poderia ser relacionada à imagem da boneca Barbie.

Não se pode, no entanto, dizer que o título antecipa o corpo do texto, pois a relação metafórica distancia uma possível hipótese sobre o que se informa, o que gera falta de continuidade temática (KLEIMAN, 2008, p. 52). Ademais, apesar de ser metafórico e de conter mais de uma expectativa de interpretação, o esforço de processamento do enunciado Barbie ganha vida não parece alto, o que permite manter a sua categoria de estímulo relevante (SPERBER; WILSON, 2005) apresentado pelo jornal.

O título não seria central do ponto de vista informativo e, por remeter a um conteúdo distinto do desenvolvido no corpo do texto, seria, então, desviante. Todavia, cumpriria ainda alguma função, que seria a de incitar a curiosidade do leitor, i. é, ele atenderia ao objetivo da captação (CHARAUDEAU, 2010).

\section{Considerações finais}

Neste trabalho, realizamos um estudo sobre a construção de títulos no jornalismo popular. Em tais enunciados, destacamos a oferta de informações que se configuram como relevantes, pois o contexto de sua produção conduz o leitor a selecioná-las como importantes e associá-las a outras já armazenadas em sua memória e, assim, gerar inferências sobre o conteúdo temático das notícias.

Nas ocorrências analisadas, destacou-se nos títulos e nas imagens inputs para a interpretação desviante do título. Tais elementos, que se materializaram em imagens, cores e signos verbais, são capazes de figurar como centrais no processo cognitivo de elaboração de hipóteses de leitura na atividade inicial de processamento do texto.

Assim, vimos que a manchete Eliéser é bi possibilitou inferências geradas entre os elementos formais propostos e informações cognitivas disponíveis. Foi a partir desse diálogo entre dados ostensivos da superfície material do texto operados em um processo cognitivoinferencial que se puderam postular certos sentidos não confirmados pelo subtítulo e pela notícia veiculada. O texto, então, não versava sobre a sexualidade do participante do 
programa BBB10, como dados internos e externos ao texto permitiam supor, mas sobre sua segunda vitória no referido programa.

Na notícia Bope vai às compras na Mangueira, a manipulação da carga dramática do tema foi realizada favoravelmente à proposta do jornal de construir no título mais de uma via de leitura. No caso em questão, a opção foi por acentuar uma das possibilidades inferenciais potenciais para o processamento do título: a função de matar associada aos policiais do BOPE, sugerida tanto verbal quanto visualmente.

Como o fato noticiado resulta de uma construção e como o jornal se elabora mediante um perfil de leitor, seria possível considerar a possibilidade de o recorte sugerido atender à imagem do BOPE (talvez negativa) nas comunidades formadas predominantemente pelas classes C e D, massa consumidora do jornal.

Em Barbie ganha vida, o título foi considerado desviante por conectar o leitor a universos de significação distantes pelas explicaturas que pudesse realizar. Construído um tema global para a notícia, após a leitura do subtítulo, confirmada no corpo do texto, entendemos haver poucos elementos possíveis que gerassem efeitos cognitivos vinculados ao tema noticiado.

De acordo com a teoria, são os processos não inferenciais que constituem a base para os processos inferenciais, nos quais tanto o conhecimento do leitor quanto o contexto figuram como fundamentais no processamento do texto.

Certos títulos no jornalismo popular, portanto, para serem interpretados como unidades complexas desviantes, requerem o levantamento de informações variadas (verbais e não verbais) da superfície textual e mobilizam processos inferenciais contextuais complementares.

Finalmente, a estratégia de construção dos referidos títulos desviantes, na vertente comercial em que se insere, a nosso ver, longe de ser contrária ao processamento do texto e prejudicar essa atividade, constituirá um estímulo à curiosidade do leitor. Advirta-se, no entanto, que advém de uma "cláusula", por assim dizer, aprovada pelo público-leitor no contrato entre este e o jornal.

\section{Referências bibliográficas:}

AMARAL, Márcia Franz. Jornalismo popular. São Paulo: Contexto, 2006. 
R E V I S $\quad$ T $\quad$ A Estudos Linguísticos - N. 30-2015.2-Wagner Alexandre dos Santos Costa

CAMPOS, Jorge. Relevância, Kluges, emoções: reflexões provocativas. In: CAMPOS, Jorge; RAUEN, Fábio José (Orgs.). Tópicos em teoria da relevância. Porto Alegre: EDIPUCRS, 2008.

CHARAUDEAU, Patrick. Discurso das mídias. 2. ed. São Paulo: Contexto, 2010.

COSTA, Wagner Alexandre dos Santos; MENEZES, Vanda Cardozo de. Operações intertextuais na categoria título no jornal carioca Meia Hora. Linguagem em (Dis) curso, [S.1.], v. 14, n. 2, p. p. 233-246, Ago. 2014. ISSN 1982-4017. Disponível em: $<$ http://www.portaldeperiodicos.unisul.br/index.php/Linguagem_Discurso/article/view/23 65>. Acesso em: 12 Ago. 2015.

COSTA, Wagner Alexandre dos Santos. Do título ao texto. Do texto ao título: o processo de estabilização da referência em notícias do jornal Meia Hora. Tese de doutorado. Niterói: Universidade Federal Fluminense, 2013, 212 f.

A construção de títulos desviantes no jornalismo popular. Cadernos de Letras da $U F F, \quad$ v. 25, $\mathrm{n}^{\mathrm{o}}$ 50, p. p. 273-289, Ago. ISSN 1413-053X. Disponível em: $<$ http://www.cadernosdeletras.uff.br/index.php/cadernosdeletras/article/view/47/38> 2015 . Acesso em 10 Set. 2015.

GRICE, H. Paul. Lógica e conversação [1975]. In: DASCAL, Marcelo (Org.). Fundamentos metodológicos da linguística, v. IV: Pragmática. Campinas, SP: IEL/UNICAMP, 1982.

KLEIMAN, Ângela. Texto e leitor: aspectos cognitivos da leitura. 11. ed. Campinas, SP: Pontes, 2008.

Oficina de leitura: teoria e prática. 13. ed. Campinas, SP: Pontes, 2010.

RAUEN, Fábio José. Contribuições da teoria da relevância aos estudos da pragmática, da cognição e da textualidade: questões e propostas de trabalho. Anais do $5^{\circ}$ Encontro do Celsul, Curitiba-PR, 2003 (543-548).

SILVEIRA, Jane Rita Caetano da, FELTES, Heloísa Pedroso de Moraes. Pragmática e cognição: a textualidade pela relevância. 2. ed. Porto Alegre: EDIPUCRS, 1999.

WILSON, Deirdre; SPERBER, Dan. Relevance: communication and cognition. Cambridge, MA.: Blackwell; Oxford; Harvard University Press, 1986.

Teoria da relevância. Linguagem em (Dis)curso, [S.1.], v. 5, p. p. 221-268, set. 2005. ISSN 1982-4017. Disponível em: $<$ http://www.portaldeperiodicos.unisul.br/index.php/Linguagem_Discurso/article/view/287/30 1>. Acesso em: 12 Set. 2015. 


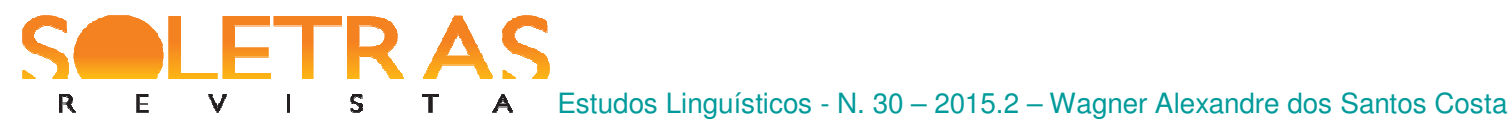

\title{
Analyzing deviant titles in the light of relevance theory
}

\begin{abstract}
This article presents a study on the relationship between the information provided to the reader and the knowledge that he deployed in reading titles of the popular newspaper Meia Hora news. We use the relevance theory, Dan Sperber and Deirdre Wilson (2005), to analyze the performance of cognitive inferential processes used to build a reading deviant hypothesis in word processing. According to the theory, it is not inferential processes that form the basis for inferential processes, in which both the knowledge of the reader as the context key figure as in word processing. Certain titles in popular journalism, therefore, to be interpreted as deviant complex units, require the lifting of various information (verbal and nonverbal) of textual surface and mobilize additional contextual inferential processes. A corpus collected between the years 2010 and 2013, we selected three instances to show that the foregoing securities contain inputs inclined to distant conclusions of the overall theme of the news. Such elements, which materialized in images, colors and verbal signs, are able to figure as central in the cognitive process of developing reading assumptions in the initial activity of text processing. They produce, in relation to the stored knowledge, inferences that can only be reformulated on the basis of processing following textual categories.
\end{abstract}

Keywords: Popular journalism. Word processing. Relevance Theory.

Recebido em: 11 de outubro de 2015.

Aprovado em: 24 de janeiro de 2016. 